Article

\title{
Optimization of Herbicide Use: Study on Spreading and Evaporation Characteristics of Glyphosate-Organic Silicone Mixture Droplets on Weed Leaves
}

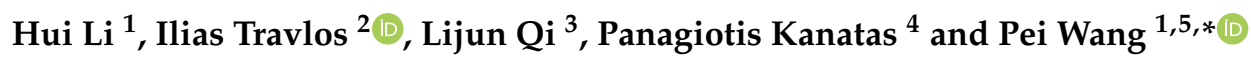 \\ 1 College of Engineering and Technology, Southwest University, Chongqing 400715, China; leehui@swu.edu.cn \\ 2 Laboratory of Agronomy, Department of Crop Science, Agricultural University of Athens, 75 Iera Odos str., \\ 11855 Athens, Greece; travlos@aua.gr \\ 3 College of Engineering, China Agricultural University, Beijing 100083, China; qlj@cau.edu.cn \\ 4 Cooperative Union of Mesolonghi-Nafpaktia, GR30200 Mesolonghi, Greece; pakanatas@gmail.com \\ 5 Key Laboratory of Plant Protection Engineering, Ministry of Agriculture and Rural Affairs, \\ Jiangsu University, Zhenjiang 212013, China \\ * Correspondence: wangpei@live.cn; Tel.: +86-188-528-98152
}

Received: 6 August 2019; Accepted: 10 September 2019; Published: 12 September 2019

\begin{abstract}
Herbicide deposition rate can be affected by the leaf surface features of weeds and have a significant impact on the overall efficacy. In this paper, an orthogonal experiment was conducted to investigate the differences of droplet evaporation and spreading characteristics corresponding to weed leaf surface with hairy, waxy and rough (ridged) structures. Three weed species-Descurainia sophia, Lepidium lotifolium, and Lolium temulentum - were included in the study, representing these three leaf structures respectively. Glyphosate sprays with organic silicone surfactant in different concentrations were composed for the test. Single droplets with two diameters of $0.05 \mu \mathrm{L}$ and $0.1 \mu \mathrm{L}$ were deposited on the leaves to evaluate the evaporation and spreading characteristics. A digital camera was used and the evaporation duration and the maximum droplet coverage images could be captured and extracted from the recorded videos. The Image Processing Toolbox in Matlab was applied to segment the images for droplet and leaf background and the binary images' pixel numbers were counted for coverage area calculation. The results revealed that the evaporation duration was reduced with the increase of the organic silicone concentration, while the spread area was expanded. The droplet spread more widely and evaporated faster on $D$. sophia leaves than on the leaves with $L$. lotifolium and L. temulentum surfaces. The spreading area and evaporation duration varied much faster on L. lotifolium leaves than on the leaves of other weed species. The droplet sizes affected spreading more significantly on L. temulentum leaf surface, as the spreading procedure of small size droplets was restrained by the groove structure. The results of this study would benefit the consideration of the farmers when selecting the proper nozzle code and the determining of the surfactant mixture in order to optimize the use of herbicides like glyphosate.
\end{abstract}

Keywords: droplet size; evaporation; herbicide application; leaf structures; spread

\section{Introduction}

The use of herbicides is important in preventing weed infestation [1]. However, there are variable control results of foliar applied herbicides in the field practice. Apart from some biotic factors like active ingredient and herbicide resistance, abiotic factors including temperature, rainfall, and deposition rate also affect the efficacy of the foliar applied herbicides [2]. Higher deposition rates reduce the total 
amount of herbicide sprayed, and higher deposition rates also benefit efficiency, since they allow a greater amount of herbicide available to be absorbed [3]. Herbicides get into the plants' physiological system by absorption $[4,5]$. Therefore, increasing the absorption ratio is one of the keys to enhancing herbicide efficacy. However, the absorption process is affected by various factors besides the deposition rate. These include environmental parameters (e.g., temperature, humidity), plant features (e.g., leaf structures, waxy layers), and spray liquid characteristics (e.g., surface tension, viscosity, chemical characteristics) [6-8].

Great differences of droplet impact and deposit characterization have been recognized on leaves with specific surfaces features [9-11]. Absorption also varies markedly on different leaves with the specific surface structures such as hairy, waxy and rough (ridged) [12]. Greater spreading ability can increase the contact area between the spray liquid and the leaf surface and this is considered to be a crucial factor affecting herbicide absorption [13,14]. Studies have shown that the ingredient could only be absorbed by plants before the droplet evaporated completely [15]. Yu et al. evaluated the droplets' evaporation and spreading process on leaves with hairy and waxy surfaces [16]. The study presented different evaporation and spread performances of droplets on the leaves with different microstructures. Long evaporation time could delay the crystallization of pesticide active ingredients and increase the pesticide absorption $[17,18]$. Thus, the ingredient absorption ratio should be different on plant tissues with specific structures. Meanwhile, several studies have shown that an addition of surfactants or higher surfactant concentration did not ensure greater coverage per se. For instance, seed oil surfactant improved the droplet spreading, while the petroleum oil surfactant had no such effect [19]. Lin et al. reported that, on adaxial surfaces, the wetted area per percentage concentration of nonionic surfactant increased with the concentration only between $0-0.25 \%$ [20]. When additional surfactant was added, the wettability improvement effect of the nonionic surfactant reduced. Organosilicone surfactant has been proved to be effective to enhance wettability of glyphosate solution. However, the wetting characteristics varies with the concentration of the organosilicone surfactant $[21,22]$. Therefore, to enhance the pesticide application effect on a specific weed species, a reasonable surfactant and proper concentration should be obtained based on the evaluation of the spreading area and the evaporation time.

Thus, in this study, experiments were carried out to investigate the different deposition effect of glyphosate droplets on weed leaves with different surface features after application. Three weed species, with hairy, waxy and rough (ridged) leaf characteristics were included in this study. The second objective of the present study was to optimize the glyphosate application parameters including the droplet size and the additive concentrations for different weeds with specific leaf surface structures.

\section{Materials and Methods}

\subsection{Plant Material and Chemicals Preparation}

Leaves with different surface structures were collected from three common weed species in fields at the growth stage of 2-3 leaves: Descurainia sophia, with hairy leaves; Lepidium lotifolium, with waxy leaves; and Lolium temulentum, with rough (ridged) leaves. All the plants were transplanted in the greenhouses in the western campus of China Agricultural University in 2017. Plants were grown in a light cycle of $16 \mathrm{~h}$ day and $8 \mathrm{~h}$ night. The temperature was kept at $25^{\circ} \mathrm{C}$ during the day and $15^{\circ} \mathrm{C}$ at night. The application was conducted one week after the transplant when the plants were at the growth stage of 3-5 leaves. The deposition and evaporation experiments were carried out in a sealed glass chamber. Inside the chamber, the temperature was set at $20 \pm 3{ }^{\circ} \mathrm{C}$ and the relative humidity was set at $65 \pm 10 \%$. Before putting the leaves onto the leaf support and releasing the droplet, the target leaves (the mature leaves) were cleaned carefully with a brush to remove the dust and washed with deionized water. When the residue of the cleaning water evaporated, the tested droplets were added onto the leaf surface with a pipette. The experimental device was set up as in Figure 1. 


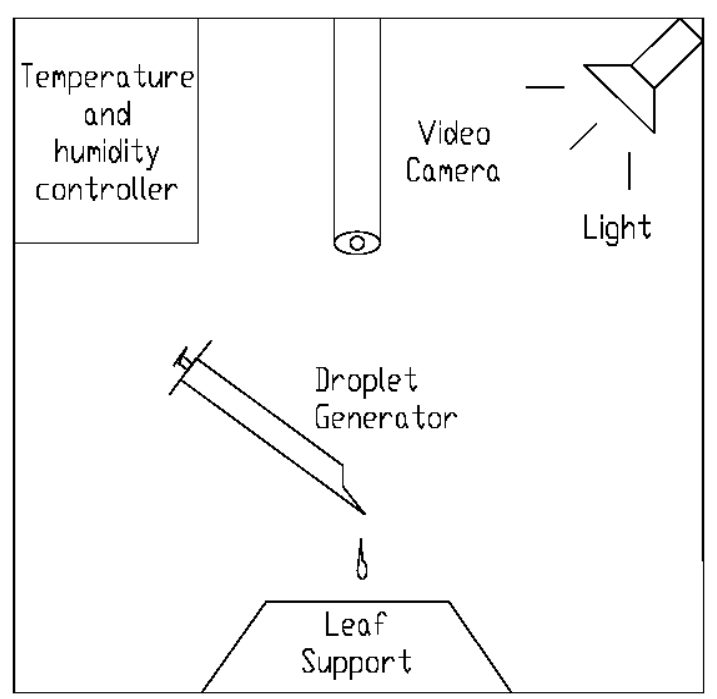

Figure 1. Diagram of the experimental setup. The testing devices were set inside a glass box, including a temperature and humidity control unit, a light supply, a leaf support and a video camera holder. Application of droplets could be seen through a window at the front of the box.

MEDA® (41\% glyphosate, Soluble Liquid, Mesa Tech International Inc, Beijing, China), Methylene Blue trihydrate (99.9\%, Tianjin No.3 Chemical Reagent Factory, Tianjin, China), silicone FY4808 (99.9\%, Guangzhou F \& Si Technology Co., Ltd., Guangzhou, China), and water were used for the preparation of the droplet liquid in this study. It has to be noted that silicone FY4808 is a widely applied organic silicone surfactant for herbicide application. Tested liquid was a mixture of $0.5 \%$ MEDA $囚$, methylene blue, and organic silicone additives. The mixture was firstly prepared with $0.05 \%$ methylene blue and $0.1 \%$ surfactant of silicone FY4808. Then the solution was diluted to five samples with surfactant concentration of $0 \%, 0.01 \%, 0.025 \%, 0.05 \%$ and $0.1 \%$ respectively. At last, $50 \mu \mathrm{L}$ of MEDA@was added to the $10 \mathrm{~mL}$ mixture. Above mixtures were prepared with $10 \mathrm{~mL}$ volumetric flasks. Table 1 shows the preparation details of the mixtures.

Table 1. Concentrations of the spray mixture components for the preparation of $10 \mathrm{~mL}$ application mixture.

\begin{tabular}{cccc}
\hline $\begin{array}{c}\text { Volume Fraction of the } \\
\text { Organic Silicone }\end{array}$ & $\begin{array}{c}\text { Mass of the Methylene } \\
\text { Blue }(\mathbf{g})\end{array}$ & $\begin{array}{c}\text { Volume of the Organic } \\
\text { Silicone }(\mu \mathrm{L})\end{array}$ & $\begin{array}{c}\text { Volume of } \\
\text { MEDA®( } \mu \mathrm{L})\end{array}$ \\
\hline Water & 0 & 0 & 0 \\
$0 \%$ & 0.005 & 0 & 50 \\
$0.010 \%$ & 0.005 & 1.0 & 50 \\
$0.025 \%$ & 0.005 & 2.5 & 50 \\
$0.050 \%$ & 0.005 & 5.0 & 50 \\
$0.100 \%$ & 0.005 & 10.0 & 50 \\
\hline
\end{tabular}

\subsection{Experimental Procedure}

Droplets with sizes of $0.05 \mu \mathrm{L}$ and $0.1 \mu \mathrm{L}$ were generated with pipettes (Biohit proline, 0.1-2.5 $\mu \mathrm{L}$, $0.05 \mu \mathrm{L}$, Biohit, Helsinki, Finland; Dragon-MED, 0.5-10 $\mu \mathrm{L}, 0.1 \mu \mathrm{L}$, DLAB Scientific Co.,Ltd., Beijing, China). Each droplet was dropped onto the leaf surface by touching in the sealed glass box. The spread and evaporation process was recorded using a digital video camera (Sony-T99, 720P, Sony Corporation, Tokyo, Japan) with an object distance of $8 \mathrm{~cm}$ and the focal length of 3.1 times. Before the droplet spreading and evaporation test, a video of a $1 \mathrm{~cm} \times 1 \mathrm{~cm}$ standard square card was taken.

\subsection{Determination of the Evaporation Duration and Spread Area}

The video data was used for the analysis. Firstly, the time when the droplet deposited on the leaf was recorded as $t_{1}$, and the time when the droplet evaporated entirely was recorded as $t_{2}$. Then the 
evaporation duration could be calculated as $t=t_{2}-t_{1}$. Three images were selected from the video of the $1 \mathrm{~cm} \times 1 \mathrm{~cm}$ standard square card with an interval of one second between each other. The picture of the maximum droplet spread area was selected from the digital video recorder using the Imaging Processing Toolbox in the Matlab platform (Matlab 2013b, MathWorks, Natick, MA, USA). Figure 2a shows the interception RGB image of the spreading part. The blue component was extracted from the RGB image and then filtered with a $3 \times 3$ Gaussian low-pass filter. The result is shown in Figure $2 \mathrm{~b}$. Then the binary image shown in Figure $2 \mathrm{c}$ was generated using the Ostu threshold segmentation method. The closing operation was applied to the binary image on a disk mask with a radius of 5 pixels. Finally, the processed pixel values were inverted to eliminate the noise, as shown in Figure $2 \mathrm{~d}$. The pixel amount could be calculated in the corresponding region of the pixel numbers, representing $1 \mathrm{~cm}^{2}$ (standard card) or the maximum spreading area (plant leaf). Droplet spreading area was calculated as follows:

$$
S=\frac{S_{\theta}}{n_{\theta}} n
$$

where

$S=$ spreading area, $\mathrm{mm}^{2} ;$

$S_{\theta}=$ area of the standard card, $\mathrm{mm}^{2}$;

$n=$ pixel amount of the spreading area;

$n_{\theta}=$ pixel amount of the standard card.
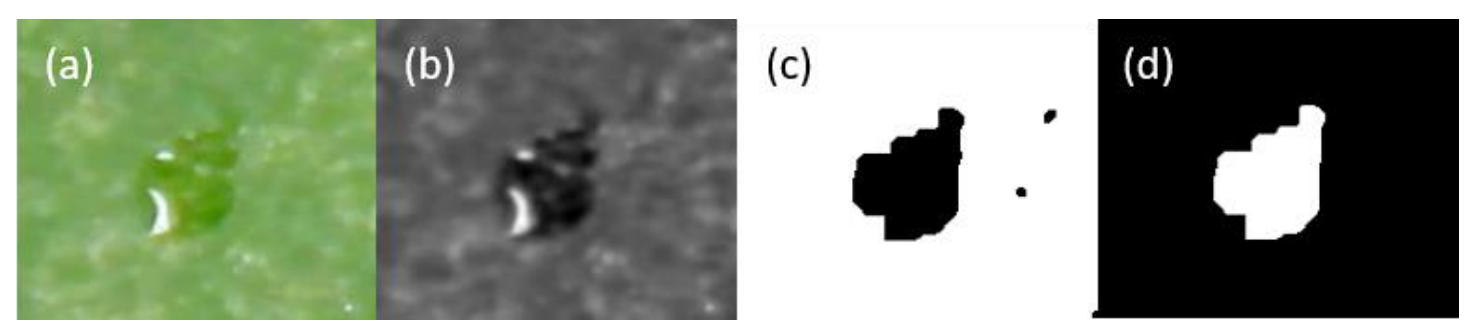

Figure 2. Comparison of the imaging processing procedure: (a) is the original RGB image, (b) is the blue component of the RGB image, (c) is the binary image generated from the Ostu threshold segmentation, and $(\mathbf{d})$ is the result of the closing operation and the inversion operation of the binary image.

\subsection{Statistical Data Analysis}

Data analysis was processed with R 3.6.3 (R Foundation, Vienna, Austria) [23]. Analysis of variance (ANOVA) was carried out for the spreading area and the evaporation duration. The leaf surface structures and the droplet size were regarded as the comparison factors respectively. Means were compared by Tukey's honest significant difference (HSD) test. Data were tested for normal distribution using the Shapiro-Wilk test $(p>0.05)$. Equality for heterogeneity of variances was tested using Levene's test for each treatment $(p>0.05)$. For the analysis of dose-response relationships, the non-linear four-parameter model was applied [24].

$$
Y=C-\frac{D-C}{1+\exp \left(b \ln \frac{x}{E D_{50}}\right)}
$$

where

$Y=$ the measuring results (the maximum spreading area or the evaporation duration);

$D=$ the upper limit of the curve;

$C=$ the lower limit;

$b=$ proportional to the slope around $\mathrm{ED}_{50}$, the dose at which the measuring result is reduced or increased by $50 \%$. 
Dose-response curves were compared by horizontal assessment ( $\mathrm{F}$ test, $\alpha=0.05$ ) after data normalization according to Streibig et al. [25]. All the experiments were conducted three times. In each repeat, five repetitions were prepared for the measurements of each treatment.

\section{Results and Discussion}

\subsection{Droplet Spreading Area}

As the object distance and focal length of the camera were constant, each pixel leaf image represented a fixed area. Thus, the droplet spreading area could be calculated by counting the pixel amount. According to Figure 3, in general, the spreading area of droplets with the same size presented significant differences on the leaf surfaces with different structures. Especially in the cases of the large droplet $(0.1 \mu \mathrm{L})$, the maximum spreading area of $D$. sophia leaves could be twice the coverage on $L$. temulentum surfaces and even four times the coverage on L. lotifolium surfaces. On leaves with the same surface structure, when the organic silicone was not added to the spray solution, there was no difference in the spreading area between pure water and the glyphosate droplets of the same size.

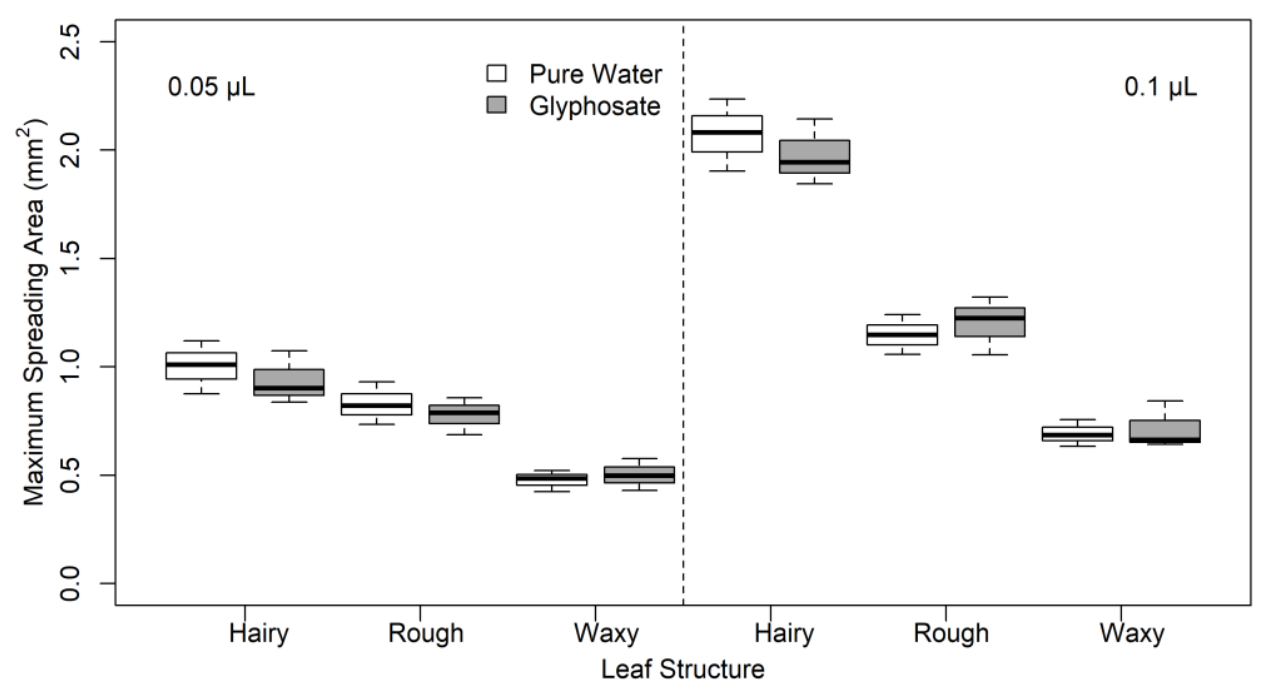

Figure 3. Boxplot of the spreading area of droplets without the surfactant additive on different leaves and in different sizes. Spreading results of the droplet with concentrations of $0.05 \mu \mathrm{L}$ and $0.1 \mu \mathrm{L}$ (left and right side of the dashed line, respectively). The lines in a bar represent the minimum, first quartile, median, third quartile and maximum (from the underside to the upside). For the leaf structure, the group names Hairy, Rough and Waxy represent the leaves of D. sophia, L. temulentum and L. lotifolium respectively.

However, according to Figure 4, when the organic silicone was added, the spreading area of the droplets with different volumes was also different even on leaves with the same surface structures. In the meanwhile, the droplet spreading area on all leaf surfaces increased with the concentration of the organic silicone. With low surfactant concentration, the spreading area increased slightly when the organic silicone fraction increased from $0 \%$ to $0.025 \%$. When the fraction of the organic silicone increased from $0.025 \%$ to $0.050 \%$, the droplet spreading area was significantly expanded. However, the spreading area expanded inconspicuously again when the surfactant concentration was higher than $0.05 \%$. The coverage variation could be attributed to the change of surface tension of the droplet, which was usually described by the Szyszkowski equation [26],

$$
\gamma_{0}-\gamma=b \gamma_{0} \lg \left(1+\frac{c / c^{\theta}}{K^{\prime}}\right)
$$


where

$\gamma=$ the surface tension of the droplet, $\mathrm{N} \mathrm{m}^{-1}$;

$\gamma_{0}=$ the surface tension of pure solvent, $\mathrm{N} \mathrm{m}^{-1}$;

$c=$ the concentration of solution, $\mathrm{mol} \mathrm{L}^{-1}$;

$c_{\theta}=$ the concentration of the standard solution, $\mathrm{mol} \mathrm{L}^{-1}$;

$b$ and $K^{\prime}$ are constants.
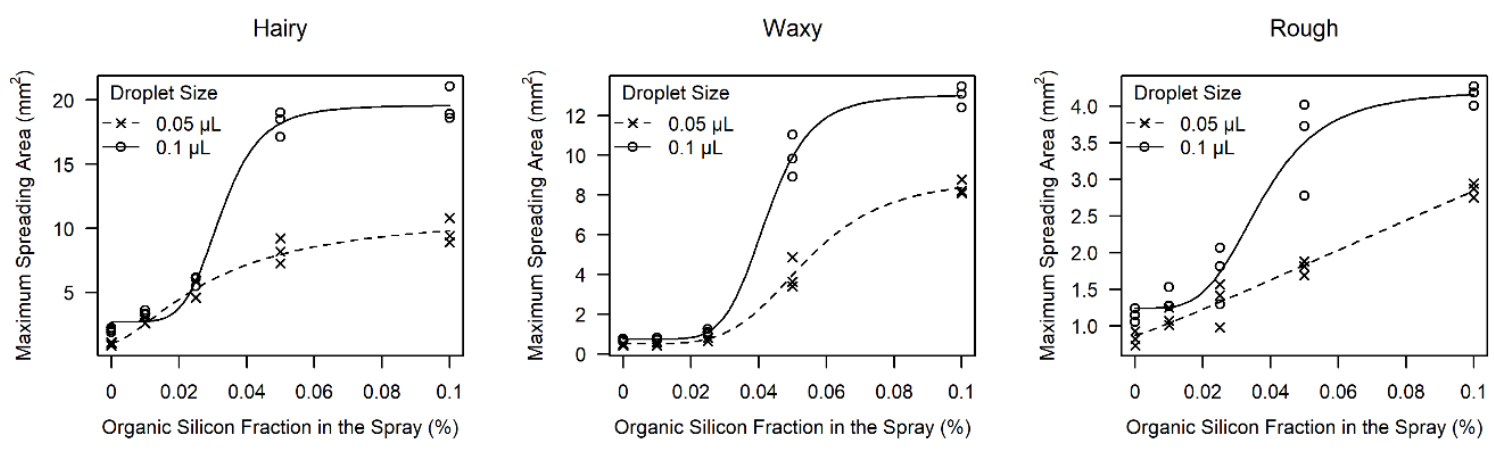

$0.05 \mu \mathrm{L}$

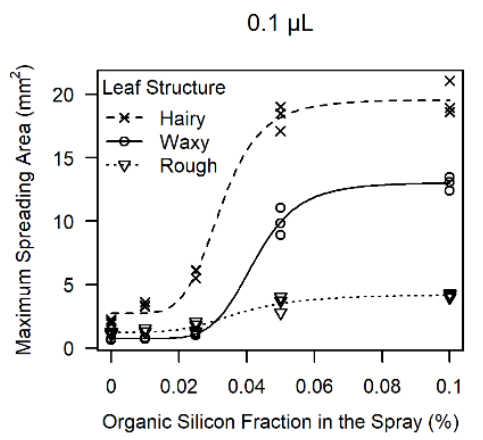

Figure 4. The comparison of the maximum spreading area of the droplets with organic silicone. The results were grouped under the leaf surface structures and the droplet sizes in each sub-figure. The droplets were prepared with the spray mixture containing the surfactant of the organic silicone with the volume fraction of $0 \%, 0.01 \%, 0.025 \%, 0.05 \%$, and $0.1 \%$. The spot marks represent the average value of each treatment in one repeat of the experiment. For the leaf structure, the group names Hairy, Rough and Waxy represent the leaves of D. sophia, L. temulentum and L. lotifolium respectively.

When the volume fraction of organic silicone is low enough, the above equation can be expressed as,

$$
\gamma_{0}-\gamma=\frac{b \gamma_{0}\left(c / c^{\theta}\right)}{2.303 K^{\prime}}=a c
$$

where $\mathrm{a}$ is a constant value.

In this low surfactant concentration case, the decrease of the droplet surface tension is proportional to the volume fraction of the organic silicone. In other words, the droplet spreading area would increase with the addition of an organic silicone fraction. However, when more surfactant was added and its concentration was up to a certain point, the tension reduction could tend to be a constant, which nearly to be zero. As a result, additional organic silicone input would not increase the coverage any more. In Figure 4, this critical point of the organic silicone volume fraction could be observed around $0.08 \%$ for $0.05 \mu \mathrm{L}$ droplets and $0.05-0.06 \%$ for $0.1 \mu \mathrm{L}$ droplets. Besides the droplet tension, the expanding ability of a droplet on leaf surfaces also depended on the surface tension of the other phases of the contact interface, including the air and the leaf surface. Antonoff's Rule and Gibbs free 
energy's variation should be considered to understand this procedure [26]. Due to the Antonoff's Rule, the surface tension at the interfaces between two phases equals to the subtraction of the two phase surface tension when exposed to the air. Gibbs free energy, which is the required energy of a liquid or air phase to expand for a unit of area on another phase, is determined by the tension differences between the two phases. Considering the Gibbs free energy's variation $(\Delta \mathrm{G})$ process during the droplet spreading, $\Delta G$ decreased with the reduction of the interfacial tension between the droplet and leaf surfaces. The droplet would spread without additional force only if $\Delta \mathrm{G}$ is zero or negative. The expression of Antonoff's Rule is [26],

$$
\gamma_{12}=\gamma_{1}-\gamma_{2}
$$

The expression of the Gibbs Free Energy's variation is [26],

$$
\Delta \mathrm{G}=\gamma_{l-s}+\gamma_{g-l}-\gamma_{g-s}
$$

where

$\Delta \mathrm{G}=$ the change of Gibbs Free Energy pre area unit during the spreading process, $\mathrm{J} \mathrm{m}^{-2}$;

$\gamma_{l-s}=$ the interfacial tension between droplet and leaf surface, $\mathrm{N} \mathrm{m}^{-1}$;

$\gamma_{g-l}=$ the interfacial tension between atmosphere and droplet, $\mathrm{N} \mathrm{m}^{-1}$;

$\gamma_{g_{-S}}=$ the interfacial tension between the atmosphere and leaf surface, $\mathrm{N} \mathrm{m}^{-1}$.

The spreading procedure could be explained by Young's Equation [26],

$$
\cos \theta=\frac{\gamma_{g-s}-\gamma_{l-s}}{\gamma_{g-l}}
$$

where $\theta=$ the contact angel.

$\cos \theta$ increased with the reduction of $\gamma_{1-s}$ and the increase of the organic silicone concentration. When the $\cos \theta$ was higher than 0 , the contact angle would be less than $90^{\circ}$. Thus, the droplet would wet the leaf surface in such a condition. In Figure 4, the droplet spreading area increased slowly at the first and end part of the curve, while increasing quickly in the middle part. Our results revealed that the expansion critical fraction of the organic silicone was between $0.025 \%$ and $0.050 \%$ under this experimental condition. This finding is in accordance with the former study by Liu et al., showing that the critical micelle concentration (CMC) is around $0.05 \%$ of a mass fraction [27]. It also demonstrated that the surfactant in the formulation of this glyphosate product is not sufficient for the good spreading effect of the droplets on leaf surfaces. When the fraction of the surfactant is less than its CMC, the surfactant mainly contributes to the reduction of the static surface tension. However, droplet spread has been attributed more to dynamic surface tension than static surface tension. The dynamic surface tension would vary more significantly when the surfactant concentration is larger than its CMC. Another novel finding of our study is the confirmation of the significant improvement of the spreading effect when the fraction of surfactant organic silicone increased from $0.025 \%$ to $0.05 \%$, which is the range containing the $\mathrm{CMC}$ value.

The droplets spread more on the D. sophia leaf surface than on the other two types of leaf surfaces (Figure 4). When the volume fraction of the organic silicone in the spray was low, compared with the leaf surface of L. temulentum, the droplet spreading area on L. lotifolium leaf surface presented no significant variation. However, the droplet coverage increased more significantly on L. lotifolium leaf surface than on $L$. temulentum leaf surface when the additive fraction increased to $0.05 \%$. The "groove structure" on L. temulentum leaves should be taken into account for the explanation of such results. In that case, the grooves were striated and this structure prevented the liquid from expanding around. Consequently, even with a silicone fraction higher than the critical concentration of the surface tension on leaves with other structures, the droplet spreading area did not increase markedly on L. temulentum leaf surface. This phenomenon tended to occur more frequently when small droplet was tested in the experiment. Nevertheless, the spreading area of large size droplets was clearly influenced by the 
silicone fraction as well, since the large size droplet might submerge the grooves that the obstruction effect on spreading was tided over.

\subsection{Droplet Evaporation Duration}

The average values of maximum evaporation duration are shown in Figures 5 and 6. According to the results, the evaporation time could be variably affected by the droplet size, leaf structure and the organic silicone fraction.
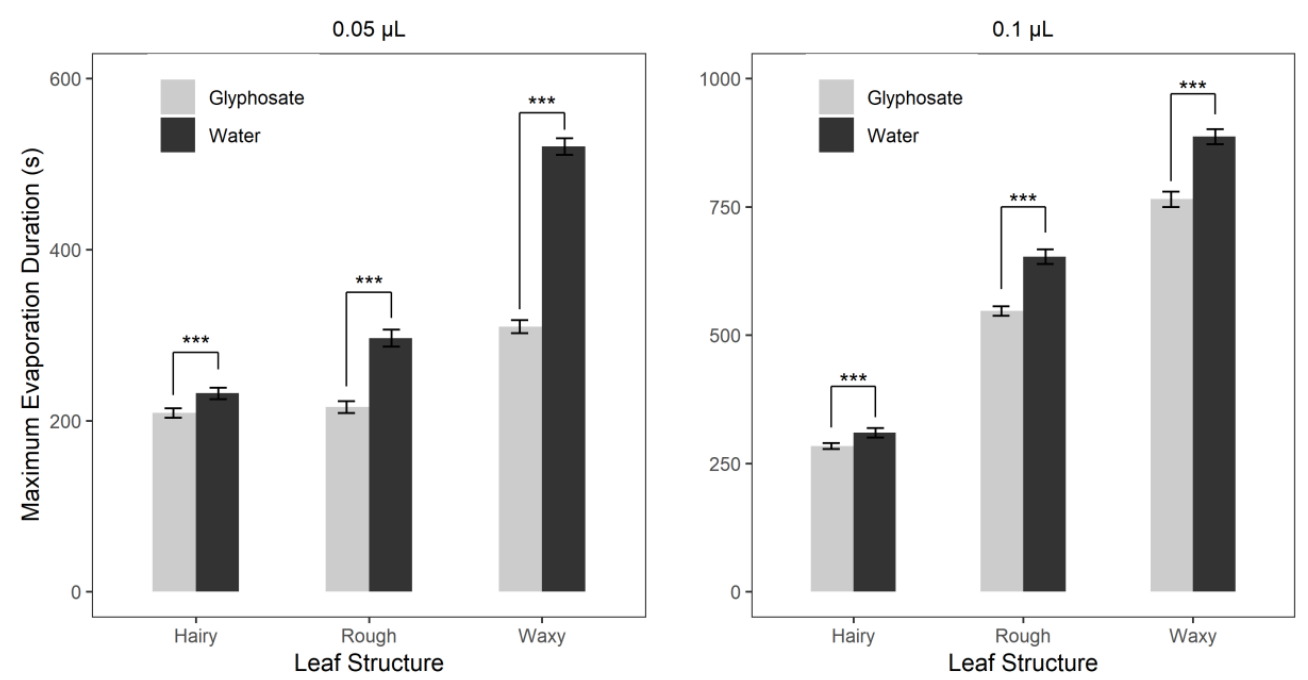

Figure 5. The maximum evaporation duration of droplets without the surfactant additives on different leaves and in different sizes. Spreading results of the droplet with $0.05 \mu \mathrm{L}$ and $0.1 \mu \mathrm{L}$ are shown (left and right side, respectively). " $\mathrm{s}$ " in the $\mathrm{Y}$-axis name represents for the time unit seconds. The mark "****" represents the significant difference of the values between each treatment according to the honest significant difference (HSD) Tukey's Test $(p<0.001)$. For the leaf structure, the group names Hairy, Rough and Waxy represent the leaves of D. sophia, L. temulentum and L. lotifolium respectively. 

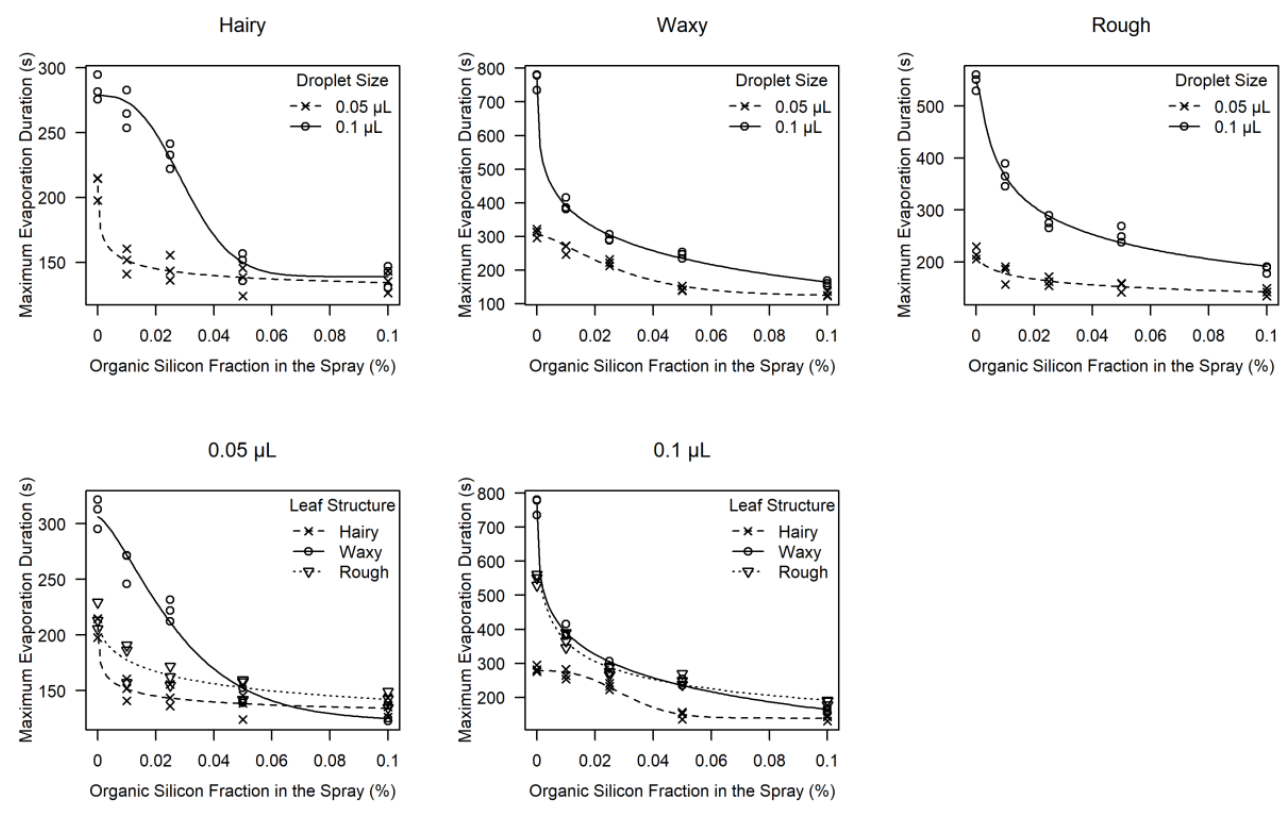

Figure 6. The comparison of the maximum evaporation duration of the droplets. The results were grouped under the leaf surface structures and the droplet sizes in each sub-figure. The droplets were prepared with the spray mixture containing the surfactant of the organic silicone with the volume fraction of $0 \%, 0.01 \%, 0.025 \%, 0.05 \%$, and $0.1 \%$. "s" in the Y-axis name represents for the time unit seconds. The spot marks represent the average value of each treatment in one repeat of the experiment. For the leaf structure, the group names Hairy, Rough and Waxy represent the leaves of D. sophia, L. temulentum and L. lotifolium respectively.

Figure 6 shows that the duration of the droplet evaporation varied obviously with the additive fraction. When the fraction of the organic silicone in the spray increased, the evaporation duration reduced. According to Figure 5, the evaporation duration of the pure water droplet was significantly higher than that of the droplets of the water-glyphosate mixture. To explain such a phenomenon, Raoult's Law should be taken into account. As the saturated vapor pressure of pure water $\left(\mathrm{p}_{\mathrm{A}}\right)$ was higher than the saturated vapor pressure of pure glyphosate $\left(p_{B}\right)$, the mixture's saturated vapor pressure $(\mathrm{p})$ decreased with water fraction's $\left(\mathrm{x}_{\mathrm{A}}\right)$ reduction. The expression of Raoult's Law is [27],

$$
\begin{gathered}
p_{A}=p_{A}^{*} x_{A} \\
p_{B}=p_{B}^{*} x_{B}=p_{B}^{*}\left(1-x_{A}\right) \\
p=p_{A}+p_{B}=p_{B}^{*}+\left(p_{A}^{*}-p_{B}^{*}\right) x_{A}
\end{gathered}
$$

where

$x_{A}=$ the volume fraction of water in the droplet mixture;

$x_{B}=$ the volume fraction of glyphosate in the droplet mixture;

$p_{A}=$ the vapor pressure of water, $\mathrm{Pa}$;

$p_{B}=$ the vapor pressure of glyphosate, $\mathrm{Pa}$;

$p_{A}{ }^{*}=$ the saturated vapor pressure of water, $\mathrm{Pa}$;

$p_{B}{ }^{*}=$ the saturated vapor pressure of glyphosate, $\mathrm{Pa}$;

$p=$ the saturated vapor pressure of the mixture, $\mathrm{Pa}$. 
As is expressed in the Clausius-Clapeyron Equation, the decrease of mixture's molar enthalpy of vaporization led to liquid's evaporation. The expression of the Clausius-Clapeyron Equation is [27],

$$
\frac{\mathrm{d} \ln p}{\mathrm{~d} T}=-\frac{\Delta_{\text {vap }} H_{m}}{R T^{2}}
$$

where

$\Delta_{\text {vap }} H_{m}=$ the standard molar enthalpy of vaporization, $\mathrm{J} \mathrm{moL}^{-1}$;

$T$ = environmental temperature, $\mathrm{K}$;

$R=$ Boltzman constant, $\mathrm{J} \mathrm{moL}^{-1} \cdot \mathrm{K}^{-1}$.

The molar enthalpy of vaporization of the mixture reduced after the organic silicone additive was added. In parallel, the additive reduced the mixture's surface energy that would accelerate the spreading and evaporation. As shown in Figure 6, the droplet evaporated faster on D. sophia leaf surface than on L. lotifolium or the L. temulentum leaves. When the organic silicone concentration in the mixture was low, on the surface of $D$. sophia leaves, droplets were hung in the air with the support of the trichomes. In this case, the droplets were completely exposed to the air and could not reach the mesophyll part of the leaves. As a result, the droplet's evaporation duration on the D. sophia leaves should be shortened. Results in Figure $6(0.05 \mu \mathrm{L})$ presented that the droplets' evaporation duration on L. lotifolium leaf surface was significantly higher than that on other leaf surfaces, with the conditions that the droplet size was small and the organic silicone fraction was low. The only exception to this was the $0.05 \mu \mathrm{L}$ droplet on L. lotifolium leaves, when the organic silicone concentration was low enough, the droplet hardly spread on L. lotifolium surface. Therefore, its contact interface between the droplet and the air was small, which led to the long evaporation duration. However, the evaporation effects were similar on all structure surfaces when the organic silicone fraction was over $0.05 \%$. Due to Figure 4 $(0.05 \mu \mathrm{L})$ and Figure $6(0.05 \mu \mathrm{L})$, the evaporation duration became shorter with a similar expanding effect on the leaves with any structure when the organic silicone fraction was over $0.05 \%$. The surface energy might not be able to prevent the droplet from expanding any more if the fraction of the organic silicone was over the critical volume fraction.

In the case of larger sizes, droplets with no additives evaporated more quickly on $D$. sophia leaf surface than on L. temulentum leaf surface. The trichomes could not support the droplet anymore as both the weight and volume were increased. In this case, the droplet was able to deposit onto the mesophyll part and the evaporation area expanded at the same time. So, the different evaporation effects were observed, compared with the droplets with smaller size.

\subsection{Surfactant Application by Leaf Structures}

According to the results presented in Figures 4 and 6, it could be summarized that the increase of surfactant concentration would improve the droplet coverage on plant leaves. On the contrary, it also shortened the evaporation duration, which limits the absorption of herbicide ingredients by the weeds [16]. Under the same application conditions and with the same parameters, the droplet spread coverage was higher and the evaporated duration is lower on D. sophia leaf surface. Consequently, when controlling the weeds like $D$. sophia, farmers may consider a large size droplet and take a low concentration of organic silicone to obtain longer evaporation. Such information would be valuable for the effective control of noxious weeds like Conyza spp. [28]. Regarding L. lotifolium leaf surfaces, the droplets' spreading and evaporation process were significantly influenced by the fraction of the organic silicone. In this study, $0.05 \%$ was the critical volume fraction of the organic silicone surfactant. For droplets in size of $0.05 \mu \mathrm{L}$, there were no significant differences in the spread coverage and evaporation duration when the volume fraction of the surfactant was higher than $0.05 \%$. Therefore, droplets of $0.05 \mu \mathrm{L}$ with surfactant in the maximum fraction of $0.05 \%$ should be selected for the control of weeds with L. lotifolium leaves. The spreading area of the droplet with smaller size was influenced by the "groove structure" on the surfaces of L. temulentum leaves. However, the evaporation duration was 
stable during the variation of the surfactant concentration. Droplets of $0.1 \mu \mathrm{L}$ spread well when the organic silicone fraction was in the range of $0.025-0.05 \%$. The evaporation time of large droplets on $L$. temulentum leaf surfaces was similar with L. lotifolium leaves in same conditions. Thus, droplets with organic silicone fraction between $0.025-0.05 \%$ and large size might be selected when controlling the weeds like L. temulentum. However, it should be emphasized that, as the results in this paper were obtained with the study of single droplet, field tests should be conducted to verify these suggestions in the following studies.

\section{Conclusions}

According to this study, we can conclude that the addition of surfactant could enhance the droplet coverage on weed leaves, which would enable the weed to absorb more active ingredient (glyphosate in our case). However, the high concentration of the surfactant could also shorten the evaporation duration of the droplets. Our findings also revealed that the droplet spreading effect and evaporation duration varied significantly on leaves with different surface structures and different droplet sizes. Such different responses can merely explain the regular failures of weed control after the use of herbicides (without a previous history of long-term use and herbicide resistance). Consequently, in order to make proper herbicide application, a reasonable surfactant concentration and nozzle code should be suggested due to the leaf features of specific weeds and therefore this is a crucial parameter that should be taken into account towards integrated weed management, optimization of herbicide use and herbicide resistance management.

Since the study in this paper was conducted with single droplet and under controlled experimental environment, field experiments are worth being carried out to determine the optimized surfactant concentration of any specific weed and under the application conditions at any specific site.

Author Contributions: Data curation, P.W.; funding acquisition, H.L., L.Q. and P.W.; investigation, H.L. and P.W.; methodology, L.Q.; resources, I.T. and P.K.; supervision, L.Q.; writing-original draft, H.L. and P.W.; writing-review and editing, H.L., I.T., P.K. and P.W.

Funding: This research was funded by the National Key Research and Development Plan of China (2017YFD0701400 and 2016YFD0200700), the Fundamental Research Funds for the Central Universities (SWU116060) and the Advanced Talent Research Funding of Jiangsu University (5501200004).

Acknowledgments: The authors would like to thank Ronghua Ji, Xia Liang, Jun Wang and the colleagues of the China Agricultural University for technical help.

Conflicts of Interest: The authors declare no conflict of interest.

\section{References}

1. Gianessi, L.P. The increasing importance of herbicides in worldwide crop production. Pest Manag. Sci. 2013, 69, 1099-1105. [CrossRef]

2. Zhu, J.; Wang, J.; DiTommaso, A.; Zhang, C.; Zheng, G.; Liang, W.; Islam, F.; Yang, C.; Chen, X.; Zhou, W. Weed research status, challenges, and opportunities in China. Crop Prot. 2018. [CrossRef]

3. Wise, J.C.; Jenkins, P.E.; Schilder, A.M.; Vandervoort, C.; Isaacs, R. Sprayer type and water volume influence pesticide deposition and control of insect pests and diseases in juice grapes. Crop Prot. 2010, 29, 378-385. [CrossRef]

4. Nandula, V.K.; Vencill, W.K. Herbicide absorption and translocation in plants using radioisotopes. Weed Sci. 2015, 63, 140-151. [CrossRef]

5. Hennigh, D.S.; Al-Khatib, K.; Currie, R.S.; Tuinstra, M.R.; Geier, P.W.; Stahlman, P.W.; Claassen, M.M. Weed control with selected herbicides in acetolactate synthase-resistant sorghum. Crop Prot. 2010, 29, 879-883. [CrossRef]

6. Chachalis, D.; Reddy, K.N.; Elmore, C.D. Characterization of leaf surface, wax composition, and control of redvine and trumpetcreeper with glyphosate. Weed Sci. 2001, 49, 156-163. [CrossRef]

7. Wang, C.J.; Liu, Z.Q. Foliar uptake of pesticides-Present status and future challenge. Pestic. Biochem. Phys. 2007, 87, 1-8. [CrossRef] 
8. Patel, M.K. Technological improvements in electrostatic spraying and its impact to agriculture during the last decade and future research perspectives-A review. Eng. Agric. Environ. Food 2016, 9, 92-100. [CrossRef]

9. Holloway, P.J. Surface factors affecting the wetting of leaves. Pest Manag. Sci. 1970, 1, 156-163. [CrossRef]

10. Sanyal, D.; Bhowmik, P.C.; Reddy, K.N. Leaf characteristics and surfactants affect primisulfuron droplet spread in three broadleaf weeds. Weed Sci. 2006, 54, 16-22. [CrossRef]

11. Dong, X.; Zhu, H.; Yang, X. Characterization of droplet impact and deposit formation on leaf surfaces. Pest Manag. Sci. 2015, 71, 302-308. [CrossRef] [PubMed]

12. Basi, S.; Hunsche, M.; Noga, G. Effects of surfactants and the kinetic energy of monodroplets on the deposit structure of glyphosate at the micro-scale and their relevance to herbicide bio-efficacy on selected weed species. Weed Res. 2013, 53, 1-11. [CrossRef]

13. Knoche, M.; Bukovac, M.J. Interaction of surfactant and leaf surface in glyphosate absorption. Weed Sci. 1993, 41,87-93. [CrossRef]

14. Fernández, V.; Sancho-Knapik, D.; Guzmán, P.; Peguero-Pina, J.J.; Gil, L.; Karabourniotis, G.; Khayet, M.; Fasseas, C.; Heredia-Guerrero, J.A.; Heredia, A.; et al. Wettability, polarity, and water absorption of holm oak leaves: Effect of leaf side and age. Plant Physiol. 2014, 166, 168-180. [CrossRef] [PubMed]

15. Ramsey, R.J.L.; Stephenson, G.R.; Hall, J.C. A review of the effects of humidity, humectants, and surfactant composition on the absorption and efficacy of highly water-soluble herbicides. Pestic. Biochem. Phys. 2005, 82, 162-175. [CrossRef]

16. Yu, Y.; Zhu, H.; Frantz, J.M.; Reding, M.E.; Chan, K.C.; Ozkan, H.E. Evaporation and coverage area of pesticide droplets on hairy and waxy leaves. Biosys. Eng. 2009, 104, 324-334. [CrossRef]

17. Knoche, M.; Petracek, P.D.; Bukovac, M.J. Finite dose diffusion studies: I. Characterizing cuticular penetration in a model system using NAA and isolated tomato fruit cuticles. Pest Manag. Sci. 2000, 56, 1005-1015. [CrossRef]

18. Gao, J.; Zhu, H.; Horst, L.; Krause, C.R. Determination of foliar uptake of water droplets on waxy leaves in a controlled environmental system. Trans. ASABE 2015, 58, 1017-1025.

19. Zhu, H.; Lin, J. Coverage area and fading time of surfactant-amended herbicidal droplets on cucurbitaceous leaves. Trans. ASABE 2016, 59, 829-838.

20. Lin, H.; Zhou, H.; Xu, L.; Zhu, H.; Huang, H. Effect of surfactant concentration on the spreading properties of pesticide droplets on Eucalyptus leaves. Biosyst. Eng. 2016, 143, 42-49. [CrossRef]

21. Field, R.J.; Bishop, N.G. Promotion of stomatal infiltration of glyphosate by an organosilicone surfactant reduces the critical rainfall period. Pesticide Sci. 1988, 24, 55-62. [CrossRef]

22. Zabkiewicz, J.A.; Stevens, P.J.G.; Forster, W.A.; Steele, K.D. Foliar uptake of organosilicone surfactant oligomers into bean leaf in the presence and absence of glyphosate. Pesticide Sci. 1993, 38, 135-143. [CrossRef]

23. R Development Core Team. R: A language and environment for statistical computing. In $R$ Foundation for Statistical Computing; R Development Core Team: Vienna, Austria, 2013.

24. Streibig, J.C. Herbicide bioassay. Weed Res. 1988, 28, 479-484. [CrossRef]

25. Streibig, J.C.; Walker, A.; Blair, A.M.; Anderson-Taylor, G.; Eagle, D.J.; Friedländer, H.; Hacker, E.; Iwanzik, W.; Kudsk, P.; Labhart, C.; et al. Variability of bioassays with metsulfuron-methyl in soil. Weed Res. 1995, 35, 215-224. [CrossRef]

26. Fu, X.; Shen, W.; Yao, T.; Hou, W. Physical Chemistry, 5th ed.; Higher Education Press: Beijing, China, 2006; pp. 311-343.

27. Liu, X.; Cao, A.; Yin, H.; Liu, X.; Yang, Q.; Bai, J. Study on enhancement of wetting property of herbicide on Eupatorium adenophorum spreng leaves by silicone surfactant. Ecol. Environ. Sci. 2010, 19, 692-696.

28. Travlos, I.; Cheimona, N.; Bilalis, D. Glyphosate efficacy of different salt formulations and adjuvant additives on various weeds. Agronomy 2017, 7, 60. [CrossRef]

(C) 2019 by the authors. Licensee MDPI, Basel, Switzerland. This article is an open access article distributed under the terms and conditions of the Creative Commons Attribution (CC BY) license (http://creativecommons.org/licenses/by/4.0/). 